\title{
Genetic Modification of Animals: Scientific and Ethical Issues
}

\author{
Jarrod Bailey \\ Senior Research Scientist, Cruelty Free International, United Kingdom \\ jarrod.bailey@crueltyfreeinternational.org
}

The scientific method demands a willingness to correct and integrate previous knowledge, based on observable, empirical, measurable evidence and subject to laws of reasoning; yet, it has scarcely been applied to non-human animal (hereinafter referred to as animal) research. Nevertheless, animal use in science started declining in the mid 1970s, at least in the United Kingdom, resulting in a drop in the number of animals used approaching $50 \%$ between the mid-1970s and mid 1980s (UK Home Office, 2016)_perhaps a tacit admission of problematic species differences that render animals poor models for humans. This trend was, however, reversed with the advent of genetically modified (GM) animals, animals whose genetic material has been deliberately altered in some way by insertion, deletion, or substitution of DNA. While the decline in use of non-GM animals continued steeply well into the new millennium, overall numbers have been rising for some time, solely due to increased utilization of GM animals (Ormandy, Schuppli and Weary, 2009). U K statistics for 2015 show that more than two million procedures involved the creation and breeding of GM animals, who were not subsequently used in further research (around $50 \%$ of the total); and there were 720,000 procedures on GM animals in further experiments, representing $35 \%$ of the total animals used in actual experiments (Hendriksen and Spielmann, 2014; U K Home Office, 2016). Trends in GM animal use for the rest of the world are difficult to determine due to different reporting requirements, but they are likely to be similar, with up to $50 \%$ of the approximately 13 million animals used annually in research in the European Union (EU) (Taylor and Rego, 2016), and the estimated 115 million animals used globally (Taylor et al., 2008).

This chapter aims to summarize and analyze this shift in the use of animals in experiments and, without being overly technical, to ask critically why GM 
animals have been so embraced in research. Is this justified? Have they fixed problems with species differences and made animal research more human relevant? Are there still issues with species differences, and to what extent? Does the new Clustered Regularly Interspaced Short Palindromic Repeats (CRISPR) technique help? Can GM animals ever provide data sufficiently applicable to humans? If so, what are the ethical costs? How much pain, suffering, and death is involved?

\section{What GM Animals Are, How They Are Made, and Problems of Efficiency and Specificity}

The genome-an organism's complement of genetic material comprising its entire collection of genes and associated elements-comprises long molecules of DNA, present in almost all cells. There are many genes along its length, each with a defined function(s), and serving as a template(s) for the manufacture of the proteins and enzymes that are the structural and chemical basis of life. The genes themselves are made up of subunits, called nucleotides, the exact sequence of which determines each gene's function. The human genome contains an estimated 20,000 genes and more than three billion nucleotides. Between the genes are other regions of DNA that serve, in various ways, to control the expression of those genes, i.e. when the genes are on or off, or to what degree the proteins they produce are synthesized.

Because our genes are fundamental to many normal biological processes, they are also at the root of perturbations of these processes that can cause things to go wrong, resulting in illness and diseases. Genetic studies have, therefore, been pivotal to much biomedical research, attempting to understand the basis of diseases and what can be done to prevent, treat, and cure them. Because animal approaches increasingly appear to be of poor human relevance, due to the very genetic differences that make species dissimilar and unique, some scientists have modified genes in animals used in experiments to attempt to overcome these differences and make them more relevant to human biology.

Broadly speaking, genes may be inserted or knocked in to animals, their own genes may be deleted or otherwise rendered non-functional or knocked out, or existing genes may be modified or repaired to alter their function. Creating GM animals has undoubtedly become more efficient and specific since their emergence, with the first reports of GM mice in 1974 (Jaenisch and Mintz, 1974). Much of what is involved is technical in nature, so it will 
not be discussed in detail here; suffice to say that various methods are available to introduce the DNA of interest - the DNA, synthesized in the laboratory, which will induce the desired genetic modification-into the zygotes (fertilized eggs) or embryos of the animals to be modified. Briefly, it may be injected into fertilized eggs (pronuclear microinjection) or into embryonic stem cells (ESCS or ES cells) - cells in a developing embryo with the capacity to become one of many different, specialized types of cell-that are removed from an embryo for manipulation and, subsequently, re-injected into developing embryos. These are subsequently surgically implanted into surrogate mothers, in which the embryos will develop, as intended, to term and result in live births of GM offspring. There are many welfare issues throughout this process, which are described later in this chapter. Initially, the technology was crude, with the cutting and splicing of DNA and insertion of new genes being fairly random and with concomitant high wastage of animal lives due to its lack of precision and efficiency. While gene editing in Escs improved the process, it should be noted that, "while it is commonly and frequently claimed that genome editing has become significantly (perhaps radically) quicker, cheaper, more efficient, easier to use, and therefore more accessible, care is needed when interpreting these claims" (Nuffield Council on Bioethics, 2016, Section 2.6); "progress has often been technically challenging [...] Es cells have not been obtained for most species and, even in mice, where the technology is relatively refined, it is time-consuming, expensive, variable, often highly inefficient, and requires a special skill set" (Section 1.11 Skarnes, 2015).

One important welfare issue for GM animals, aside from the obvious outcome of their genetic modification, is the poor efficiency (on-target efficiency), and associated undesired (off-target) effects, of the process. On-target efficiency has increased and off-target effects have decreased significantly with the relatively recent discovery of new methods (Hsu, Lander and Zhang, 2014), especially the RNA-guided programable nuclease gene-editing platform, CRISPR (CRISPR/Cas9 system) (see e.g., Chandrasekaran, Song and Ramakrishna, 2017). CRISPR has generated particularly significant excitement, having "swept through labs around the world", at a "breakneck pace [that] leaves little time for addressing the ethical and safety concerns such experiments can raise." (Ledford, 2015, pp. 20-21). This is because, in relation to other methods, it is less expensive (Ledford, 2015; various components of CRISPR experiments can be bought for as little as US $\$ 30$ ), less technically challenging, and less time consuming (Caplan et al., 2015). It, therefore, deserves particular attention. CRISPR derives from a bacterial immune system (Fineran and Charpentier, 2012), and has two components: a single guide RNA molecule (sgRNA), which 
is specifically designed to seek and bind to precise targets in the genome that are to be modified; and an associated enzyme, Cas9, which cuts the DNA at the target site and initiates the genetic modification process. Put simply, CRISPR causes complete (double-stranded) breaks in the DNA at (in theory) specific targeted sites, which are subsequently repaired by the cell's own DNA-repair systems.

However, the repair process is inherently error prone and generates small insertions or deletions of DNA at the break sites, which can be used to disrupt gene function or, in the presence of engineered DNA molecules introduced experimentally, to alter the DNA specifically at that site. While this method is generally considered to be much more efficient and specific compared to other approaches, any accurate, definitive, quantitative estimation of the efficiency of CRISPR is difficult to find, as estimates vary considerably and are affected by many factors, including the nature of the target site and the CRISPR molecule used. Generally, the method has improved over time, but there is a strong argument that CRISPR remains far from good enough, scientifically and ethically. One 2017 review reported that "knock-in efficiencies are still low and highly variable," with different genetic loci in zebrafish embryos having genes successfully knocked in, in $45 \%$ and $70 \%$ of cases, though only in $1.7 \%$ and $3.5 \%$ respectively, with any real precision. Associated successful germline modifications to produce founder fish for breeding occurred on average just $3.8 \%$ of the time (Albadri, Del Bene and Revenu, 2017, p. 8). Another recent study found an average of $9.2 \%$ of transferred embryos resulted in mouse pups, and an average of $76 \%$ of these had been successfully knocked out for a specific gene. The generation of pups harboring specific point mutations was lower: $6.5 \%$ of transferred embryos produced pups, though less than $8 \%$ of these had the desired mutation (Nakagawa et al., 2016). In cell lines, mutation efficiencies are generally higher, though they range from lower than $5 \%$ up to $90 \%$, and gene knock in less than $10 \%$ up to $66 \%$ (see Bortesi et al., 2016).

Regardless of on-target efficiency, one issue has plagued the creation of GM animals: off-target effects, or mutations induced by the GM process that are not intended but affect other non-specific sites in the genome (Fu et al., 2013; Hsu et al., 2013; Pattanayak et al., 2013). This is a significant scientific and welfare issue, which raises serious concerns over the wider application of genetic modification in science, medicine, and agriculture (Kanchiswamy et al., 2016; Kleinstiver et al., 2016). These concerns include: the low birth rates of animals with the desired genetic modification and the associated high "wastage", or animals that may suffer and/or be killed as a result; and many animals who harbor off-target mutations adversely affecting the animal's characteristics (phenotype) (Guha, Wai and Hausner, 2017). Significant off-target DNA cleavage 
and mutation results in toxicity to those cells in which it occurs (Kim et al., 2009), and their repair causes chromosomal rearrangements, which can activate genes that can cause cancer (Cradick et al., 2013; see also Cho et al., 2014). Not surprisingly, "major concerns of off-target mutations have been observed in medical and clinical studies," as well (Kanchiswamy et al., 2016, p. 564). This leads to difficulty in interpreting data but may also cause these animals further pain and suffering, due to the off-target effects, and death as they succumb to adverse off-target effects or are killed because they are of no experimental use.

Despite the considerable effort put into improving the situation, the extent of off-target effects is still a matter of serious debate (Bassett, 2017). Astoundingly, they are thought to be up to $50 \%$ more common than the desired on-target mutation efficiency, and they may occur at sites quite different to the target site, both of which are of serious concern (Fu et al., 2013; see also Bortesi et al., 2016; Komor, Badran and Liu, 2017). Many computational approaches to assessing potential CRISPR off-target problems exist. Though useful, each is biased regarding the type of off-target sites it may or may not fail to predict. It is therefore widely accepted that other, unbiased methods of assessment must be used to help avoid missing off-target effects that may be seen experimentally (see Bolukbasi, Gupta and Wolfe, 2016; D'Agostino and D'Aniello, 2017; Tsai et al., 2015). Some CRISPR experiments show more than 100 off-target mutations, while others appear to show none (Bolukbasi et al., 2016). Some analyses have suggested little or no off-target activity for some CRISPR molecules, though these analyses examined preselected genomic sites only so are likely to suffer from bias (see Bortesi et al., 2016). Any single technique will miss off-target sites that others will detect; and, unfortunately, the most comprehensive method - whole genome sequencing — is technically difficult and expensive. For example, a rare mutation ( $0.1 \%$ frequency) would require sequencing 1,500 genomes to give a $95 \%$ probability of finding this mutation at least once (Sluch et al., 2015).

A recent (2017) study attempted to complete a comprehensive whole-genome analysis to determine the actual prevalence of all off-target mutations in a CRISPR-edited mouse, not only the larger mutations, such as insertions and deletions (indels) of DNA but also the smaller, though no less important, single nucleotide variants (sNVs) that are often not sought. Schaefer and colleagues, reported "an unexpectedly high number of sNVs," in addition to an average of 146 indels, with many of these in known genes (Schaefer et al., 2017, p. 547). The authors concluded that "concerns persist" over the unpredictable nature of CRISPR off-target mutation sites, which were likely to have a detrimental impact on key cellular processes and would likely manifest in adverse phenotypes. This specific issue remains, however, highly controversial. In March 
2018, Schaefer and colleagues retracted their paper-in the face of pressure from some members of the scientific community working on CRISPR-on the grounds that the study results were irreproducible and unsupported by the data, and the study lacked key controls (Editorial, 2018; Schaefer et al., 2018). Retraction of this paper does not, of course, remotely prove or even suggest that CRISPR is sufficiently free of off-target effects to be safely used in humans. Most stakeholders who have opined in its wake have urged further progressive, yet cautious, research to elucidate the situation and stopped short of inferring an all clear from the authors' most recent work (Schaefer et al., 2018). With particular regard to their revision, Schaefer et al. are careful to note (correctly) that their latest data suggest that, "in specific cases, CRISPR [...] may not introduce numerous, off-target mutations" (Abstract). Others note that this simply means that the concern over off-target effects "just isn't perhaps as big as that initial study suggested." (Brown, 2018). More generally, all involved appear to accept that far too little data exist to reach any robust, definitive conclusions about off-target effects associated with CRISPR, either way. This sensible, evidence-based view is supported by the many studies that exist, with a full spectrum of results (such as those referenced in this chapter), that serve only to rubber stamp the view that this field is young, and the question of off-target effects is still completely wide open.

Crucially, just before this Volume went to press, this caution was further justified by a detailed study published in Nature Biotechnology, which showed that the specificity of CRISPR-induced genetic alternations had been overestimated to date, due to exploration of them being "limited to the immediate vicinity of the target site and distal off-target sequences" (Kosicki et al., 2018). The authors' more thorough and detailed investigations revealed that - in two different types of mouse cells and a differentiated human cell-line alike-mutagenesis at the target sites was often much more significant than intended/ expected. Instead of the aforementioned small insertions or deletions of DNA, the resulting CRISPR-mediated genetic alterations were frequently "large deletions and more complex genomic rearrangements", often extending to many kilobases. Further, off-target lesions often resulted in "genomic damage", which "may have pathogenic consequences." The important warnings of their conclusions bear repeating here: extensive on-target genomic damage is a common outcome; consequences are not limited to the target locus but will affect more distal genes; some repercussions may initiate neoplasia (cancer); it is likely that some cells in each protocol would contain important pathogenic lesions, some of which would become cancer-causing in time; and others. Such frequent and extensive genetic damage is and has been undetectable by the means often used to identify it, leading to its under-reporting and under-appreciation, and so much more comprehensive analysis of the genetic 
consequences of CRISPR experiments is warranted and necessary. This may be of urgent concern due to the fact that six clinical trials of CRISPR are currently underway, for various malignancies/cancers, including esophageal, nasopharyngeal, gastric, non-small cell lung cancer, leukemias/lymphomas and other hematological malignancies (see Clinicaltrials.gov).

Clearly, off-target mutations remain a major issue, with persistent targeting of unintended genomic loci (Bisaria, Jarmoskaite and Herschlag, 2017, p. 21; see also Tsai and Joung, 2016), even as steps are taken to mitigate their occurrence and effects, such as using engineered/modified CRISPR components (see e.g. Bayat et al., 2017; Chandrasekaran, Song and Ramakrishna, 2017; Combes and Balls, 2014; Ding et al., 2016; Guha, Wai and Hausner, 2017). It is widely believed that the factors controlling CRISPR's precision and accuracy "are still not fully understood," and obstacles remain on the path to any clinical application (Jiang and Doudna, 2017, p. 524). "Much remains to be learned regarding the efficiency and specificity of CRISPR/Cas9-mediated gene editing in human cells, especially in embryos." (Liang et al., 2015, p. 364) It is considered "necessary" to develop methods of detecting off-target mutations that are much more sensitive (Tsai and Joung, 2016, p. 310); but it is also thought that these will never be removed completely (Bassett, 2017), and that off-target effects will still occur often, no matter how high the on-target specificity (Liang et al., 2015). Off-target mutations remain stubbornly numerous and confounding in spite of many, multi-faceted efforts to reduce them and their impact; and this may have serious consequences for the use of CRISPR, even in laboratorybased research, where there will be more acceptance of them. This means that the role of off-target effects in any observations cannot be ruled out, but especially in clinical settings, where safety is paramount and even off-target mutation frequencies as low as $0.1 \%$ can have serious consequences (Tsai and Joung, 2016).

Finally, shortly before this Volume went to press, yet another, but different, clarion call for great caution came in the form of two papers published in Nature (Ihry et al., 2018; Haapaniemi et al., 2018). The double-strand DNA breaks created by CRISPR/Cas9 as part of its mechanism of action activate a gene called p53, which is known as the "guardian of the genome"-involved in the repair of DNA damage and, if that damage is sufficiently significant, in apoptosis, or the destruction of the cell containing the damaged DNA. It is because of these functions that $\mathrm{p} 53$ - a tumor suppressor gene-is known to be mutated in more than half of all human cancers (Hollstein et al., 1991; Foronda and Dow, 2018); if p53 cannot carry out its normal activities, damaged cells may go on to become tumorous (Ferrarelli, 2018). This is an issue because, as one might expect, p53 blocks CRISPR/Cas9 activity; and it therefore follows 
that cells that are experimentally modified by CRISPR, must, thus, tolerate DNA damage, and so must have deficient $\mathrm{P} 53$. In selecting for CRISPR-modified cells, therefore, one may be selecting for cells that could lead to tumor formation, which could be clinically catastrophic. As one of the authors opined, "By picking cells that have successfully repaired the damaged gene we intended to fix, we might inadvertently also pick cells without functional p53. If transplanted into a patient, as in gene therapy for inherited diseases, such cells could give rise to cancer, raising concerns for the safety of CRISPR-based gene therapies." (Karolinska Institutet, 2018).

It has been suggested that such cells could be identified and eliminated by in vitro screening (Foronda and Dow, 2018), but various problems remain. Just one, single DNA break seems to be sufficient to prime p53 activity, and lead to cell arrest or death (Foronda and Dow, 2018; Ihry et al., 2018), so the problem may be greater than first thought. Some have inferred or implied that this is a new discovery, but it is not: almost quarter of a century ago, this was demonstrated in human fibroblasts (Di Leonardo et al., 1994). Further, CR ISPR-editing issues were reported in 2016 with some types of cells, including primary and stem cells (Hockemeyer and Jaenisch, 2016; Carroll, 2018), the latter being the type of cell involved in one of the recent Nature papers (Ihry et al., 2018) - so this may be another illustration of lack of caution among some CRISPR researchers and advocates, and further reason to doubt that due caution and critical approach are being applied widely enough — particularly as the underlying mechanism was not pursued (Carroll, 2018). As stated in a recent, highly relevant review, "It is surprising that this phenomenon was not recognized much earlier." (Carroll, 2018). Because break-induced toxicity has not been detected in all cell types, but also due to it not being seen in some cell types that do have functional p53, it means that "the induced arrest phenomenon will have to be tested and addressed for each type of target cell" as "that pathway is not the whole story" (Carroll, 2018). Finally, while selection is possible in vitro, it is not an option for in vivo somatic gene correction, in which this would have serious consequences for animals and humans (Foronda and Dow, 2018).

\section{Current and Intended Uses of GM Animals}

\subsection{Biomedical}

Many GM animals are used in basic research with no direct application (for example, to a particular therapy for a specific disease), but with aims to investigate the functions of particular genes, for example, and the nature of their regulation. Others are used as specific models for many different human diseases, 
including multiple infectious diseases, such as HIV, immune system defects, blood and metabolic disorders, muscular dystrophy, cancer immunotherapies, among others (Cornu, Mussolino and Cathomen, 2017). Gene therapy interventions for some of these diseases have already reached clinical trials, such as HIV/AIDS therapies (Cornu, Mussolino and Cathomen, 2017); though there are some serious concerns over potential immune reactions in humans to two of the most common proteins used in the CRISPR/Cas9 system. Recent analysis of human blood samples revealed the presence of antibodies to Cas9 proteins in $65 \%-79 \%$ of individuals; and around half of all the blood samples harbored immune cells with the potential to destroy human cells, containing one of the Cas9 proteins (Charlesworth et al., 2018). The potential severity of any immune reaction in patients is unknown, but it could range from making CRISPR nonfunctional, to dangerous inflammatory reactions.

Efforts are being made to use CRISPR to deactivate and render some viruses non-infectious and/or non-pathogenic, such as hepatitis $B$ and $C$ viruses and HIV (Doerflinger et al., 2017; Huang et al., 2017; Li et al., 2017; Moyo et al., 2017; Soppe and Lebbink, 2017). Serious caution has been advised, however, due to the risk of causing mutations that increase, rather than decrease, virulence (Wang et al., 2016). It is claimed that CRISPR holds the key to translating data from rodent models of psychiatric disorders and neurobehavioral traits to humans, including disorders associated with anxiety, mood, and substance and impulse-control (Baud and Flint, 2017, p. 373). CRISPR's potential for cancer biology has been expounded, as it can recreate potential cancer-causing mutations identified in human tumors, in both cell lines and GM animals (Guernet and Grumolato, 2017). Some GM animals are used in attempts to produce medically important proteins, for example, in cows' milk, which can be generated in high volumes and purified from the milk for clinical use. Examples include treatments for some blood disorders, osteoporosis, and emphysema (Moura, Melo and de Figueiredo Freitas, 2011). GM animals are central to efforts to use animals as a source of organs for human transplantation (xenotransplantation), targeting biological pathways involved in immune rejection of transplanted organs.

\subsection{Farm/Food Animals}

A major application of GM technology ( $\mathrm{GM}$ also can mean genetic modification or manipulation, as well as genetically modified) is the engineering of animals used for food (Ledford, 2015). Examples include, chickens producing only female offspring for egg-laying, cows producing only male offspring for better meat yield, pigs who can be fattened with less food, cashmere goats producing more meat from greater muscle mass and longer hair for greater wool yield; 
and efforts to facilitate greater stocking density, such as cattle without horns and animals with greater resistance to disease (see Frewer et al., 2013; Nuffield Council on Bioethics, 2016). Double-muscled pigs (Cyranoski, 2015), rabbits (Lv et al., 2016), sheep and cows (Proudfoot et al., 2015; Luo et al., 2014) have been created for human consumption, though many died early and were unhealthy, and birthing difficulties occurred due to their size (Cyranoski, 2015). Cows without horns can be housed more densely with lower risk of goring injuries (Loria $\mathrm{K}$, 2016; Carlson et al., 2016). While there may be welfare benefits-millions of cattle would no longer need to be dehorned, which can be very painfulthey would be farmed more intensively and have less space to live in, further compromising their welfare. Other efforts include cows that produce milk that does not induce allergies in humans (Yu et al., 2011); milk with altered fatty acid content, and milk that contains high levels of lactoferrin (Yang et al., 2008a); cows who produce "tastier beef" because their flesh contains more fat (Guo et al., 2017); and pigs who bleed out more efficiently at slaughter (Hai et al., 2014) and have omega-3 fatty acids in their flesh (Lai et al., 2006). GM salmon, modified so that they grow at twice the rate of normal salmon and can be housed in tanks on land, have been approved for human consumption in the United States (US) (Connor, 2015). Much of this is undoubtedly the result of lobbying by vested interests that stand to profit from these projects, who assert that, for instance, the Earth's growing population and shifting appetites will necessitate considerable increases in food production that cannot be achieved by any other means alone; yet, there is strong counter evidence and opinion that alternative strategies could meet that need, such as reducing food wastage; changing consumer demand and preferences for meat, dairy, and eggs; and improving farming and production methods by other means (High Level Panel of Experts on Food Security and Nutrition, 2014). Despite the potential for both direct and indirect effects on animal welfare in this area, it is acknowledged that too little attention has been devoted to the genetic modification of "farm animals" and to the regulation of the practice (Nuffield Council on Bioethics, 2016).

However, the creation of GM animals commonly used for food is not limited to making them easier to manage or more profitable for their meat and milk. Pigs are touted as being more appropriate models of human diseases than mice, for example, for cystic fibrosis, cancer, diabetes, neurological disorders, high cholesterol, and muscular dystrophy; while a gene associated with achondroplasia has been targeted in cattle (Carlson et al., 2012; Petersen and Niemann, 2015).

\subsection{Dogs and Monkeys}

Concerns that less strict regulations in countries outside of the EU and the Us may lead to GM projects that may not be approved elsewhere appear to 
have substance. Prior to CRISPR, a Chinese group created transgenic dogs who emitted red fluorescent light (Hong et al., 2009). This was far from efficient. 344 embryos transferred to 20 surrogate mother dogs, resulted in seven pregnancies and six live births. More recently, another Chinese laboratory created GM dogs using CRISPR, knocking out a gene controlling muscle growth, resulting in dogs who were "much more muscular" (Doane, 2016; Zou et al., 2015). Their work was defended via a tenuous link to the creation of future dogs who could model, for example, Parkinson's disease; but only two of 60 edited embryos were "successful." Elsewhere in China, GM monkeys have been created with apparently similar characteristics to autism. Eight macaques (out of "dozens" of GM embryos) were born with a gene (MECP2) linked to autism in humans, who showed signs such as running "obsessively in circles", ignoring their peers, and grunting anxiously when stared at (Cyranoski, 2016b; Liu et al., 2016; Snowdon, 2016).

Interestingly, when espousing the use of "large animals" as GM models for human diseases, those who may otherwise stoutly defend GM mice are open to criticizing them. For example, one recent paper, authored by scientists creating GM livestock, noted that "the drawbacks of using rodents to model humans are well established [...] mice make poor models for reproductive physiology, pulmonary problems, metabolic regulation, and many other fields of inquiry" (West and Gill, 2016). Unfortunately for such advocates, as discussed in this chapter and in works referenced in it, it appears that "larger animals", GM or not, remain poor models for these areas and more, and can only ever be so. This is compounded by the same, or even greater, confounding issues of low efficiency and a variety of limitations and complications (see section on nonhuman primates, NHPs, below).

\section{Suffering, Welfare, and Ethical Issues with GM Animals}

Many animal researchers acknowledge that creating GM animals involves suffering at every step, from generating sufficient eggs to embryos for modification, through to the pain and suffering experienced by many progeny (Laboratory Animal Science Association, 2008; Robinson, Jennings and Working, 2004).

\subsection{Breeding and the GM Process}

Producing eggs for the embryos used in the GM process involves drug-induced superovulation of females, whose fertilized eggs are collected post-mating, which may involve killing the females, a common practice in rodents, or at least surgery under general anesthesia (more "valuable" species). Approved killing methods for rodents are, commonly, neck dislocation or carbon dioxide 
suffocation, which can both (not surprisingly) cause distress (Robinson et al., 2004). Both superovulation and fertilized-egg collection can cause discomfort, stress, and post-operative pain (Camara, et al., 2008). After modification, embryos are implanted into surrogate mothers in the form of pseudopregnant females, who have been previously mated with vasectomized males (The Boyd Group, 1999). Pre- and post-natal death of offspring may be significant. One report showed that an average of just $29 \%$ of implanted embryos survived to weaning, and only a quarter of these ( $7 \%$ of implanted embryos) (Hubrecht, 1995), or an average of $15 \%$ ( Robinson et al., 2004), may be GM. Miscarriages may cause pain and distress, and such poor efficiency means that many donor and recipient animals must be used to produce a relatively small number of desired GM individuals. Genotyping of resultant offspring may involve blood sampling or tissue biopsy. Invasive methods are still common, including tail snipping, ear snipping/punching, or even toe amputation, all causing pain in mice (Robinson et al., 2004). The genetic modification process has been documented, at least in larger animals, such as sheep and cattle, as a factor in increased gestation length, greater body weight, risk of dystocia (difficult birth), and various perinatal anomalies and loss. In mice, there is also evidence of increased embryonic and fetal loss (Camar et al., 2008).

\subsection{Animal Lives Wasted}

The persistent inefficiency of the GM process is a serious welfare issue (Boyd Group, 1999; Camara et al., 2008; Laboratory Animal Science Association, 2008; Robinson et al., 2004). It is difficult to quantify, as many countries do not require the reporting of GM-animal statistics (Taylor et al., 2008). In the UK, statistics indicate a high degree of wastage (around $50 \%$ of a total of more than 4 million animal procedures in 2015, involved the creation and breeding of GM animals not used in subsequent experiments), and specific GM license applications are revealing: seven projects from 2014-2015 proposed using a total of almost 27,000 animals ( UK Home Office, 2014).

\subsection{Effects of Genetic Modification}

Inserted genetic material may have adverse effects on GM embryos/animals. Some may be unpredictable, such the aforementioned off-target effects; while others are expected and the result of on-target effects, such as GM mice who will develop painful cancers. Naturally, the GM process may not necessarily adversely impact welfare; but the critical point is that, frequently, the welfare consequences of the GM process cannot be predicted in detail, nor can they be assessed properly. Welfare assessments are by their nature wide open to subjectivity and opinion, and much more research needs to be done in this 
area to increase objectivity, if indeed this is possible to any significant degree (Hawkins et al., 2011, Wells et al., 2006). Therefore, it is acknowledged that reduced viability or impaired health may be expected (Bundesamt für Veterinärwesen, 2006); while some estimates suggest around $20 \%$ of GM animals suffer minor discomfort, $15 \%$ severe discomfort, and $30 \%$ increases in mortality and susceptibility to disease (Thon et al., 2002).

Indications may include, for instance, developmental abnormalities, such as cleft palate; perinatal and post-weaning mortality; skeletal abnormalities, including malformed limbs; discharge from eyes and ears; diarrhea; poor posture, gait, and ataxia; stereotypies, such as lack of alertness, poor or over-grooming, circling in cage; absence of teeth; poor mothering; poor thermoregulatory ability; enhanced growth of tumors and development of metastases, often at atypical sites; increased aggression; seizures; a range of diseases, including diabetes, osteoporosis, degenerative joint disease, inflammatory bowel disease, and ulcerative colitis; sensory and locomotor abnormalities affecting sight, hearing, smell, balance, and social interactions; and increased incidence of infectious disease (Dennis, 2002). GM mice databases reveal progressive hearing loss and deafness; development of diabetes; impaired movement and coordination, including tremors and involuntary movements, difficulty in initiating movement, abnormal posture, and paralysis; susceptibility to infectious disease; colitis; progressive muscle weakness; kidney inflammation; premature death; intestinal obstruction; respiratory distress; hyperactivity; heart failure; internal bleeding/brain hemorrhage; self-harm; seizures; vision problems and blindness; and many more (e.g., Mouse EnCODE Consortium, mouseencode. org; Mouse Genome Informatics, MGI, database, informatics.jax.org). The Mouse Genome Informatics (MGI) database lists mice under the following categories (among others): with abnormality of blood, connective tissue, head or neck, limbs, metabolism, prenatal development/birth, cardiovascular system, digestive system, ear, eye, genitourinary system, immune system, musculature, nervous system, respiratory system, skeletal system, and cancers. The scale of this must also be mentioned: as of July 2017, the MGI database cites 51,000 mutant alleles in mice, with more than 3,10o human disease models; the International Mouse Strain Resource (findmice.org) lists around 40,000 strains as available worldwide; the International Knockout Mouse Consortium has generated around 5,00o mutant mouse lines (Rosen, Schick and Wurst, 2015); and the International Mouse Phenotyping Consortium intends to generate 20,000 knockout mouse strains (mousephenotype.org) (Koscielny et al., 2014).

Off-target modifications may induce mutations that abrogate gene function and/or cause rearrangements of the genome with other, subsequent mutational effects on other genes. In assessing effects of GM on welfare, it has been 
cautioned that setting a "normal" baseline must be done carefully. For example, it is normal for GM mice engineered to have vestibular abnormalities to spend much time circling in their cages. This may be normal for these mice but should not be considered normal from a welfare perspective (Hawkins et al., 2011).

\subsection{Increasing Numbers of GM Animals}

Many of these welfare issues are not exclusive to CRISPR and exist for other GM methods. It has been argued that CRISPR should mitigate many of these, with its simplicity and greater efficiency, and so should be welcomed by animal advocates. To some extent this may be true, in time. However, the corollary gives great cause for concern, that this simplicity and efficiency will also "not only increase in the range and diversity of transgenic rodent strains but will greatly expedite transgenesis in other species, including non-human primates" (Combes and Balls, 2014, p. 137). In this regard, CRISPR is described as a mixed blessing (Hendriksen and Spielmann, 2014); and animal ethicist Bernard Rollin (2015) accepts that easier GM techniques would undoubtedly lead to an increase in the number of animals used "as more researchers engage in hitherto impossible animal research". It has been said that CRISPR will revolutionize mouse genetics by reducing the time it takes to create a new GM model from years to months, or even weeks (Fellmann et al., 2017). In other words, for any reduction and refinement in any specific GM experiment due to CRISPR, a greater overall number of GM experiments will offset this, compounded by more experiments on a wider range of species, including dogs and monkeys.

This is not mere speculation. Aside from being logical, and in addition to multi-stakeholder enthusiasm for CRISPR and associated market projections, it is clear from current scientific literature. Many speculative claims for CRISPR reflect an excitement that, in part, is responsible for the great expansion of interest in the technology and in the creation of greater numbers of GM animals in academe, biotech firms, and large pharmaceutical companies (Cornu et al., 2017). For example, it is estimated that by 2021, the GM market will be worth US $\$ 6.28$ billion (MarketsandMarkets, 2017). It has, therefore, been strongly suggested that the welfare consequences of genetic modification for all species should be monitored and explored in greater detail. Perhaps, at least, an in-depth, systematic, critical assessment of the rationale for using GM animals in human disease research is warranted; and projects involving GM animals should be approved only in "extremely exceptional circumstances" (Combes and Balls, 2014, p. 143; see also Mepham et al., 1998). Unfortunately, interest in CRISPR is, at least for now, manifesting in substantial animal use. The scientific literature shows (as of June 2017) more than 6,00o publications, up from fewer than 4,00o just a year earlier (June 2016), and just over 6oo, 18 months prior to that (Nuffield Council on Bioethics, 2016). 


\subsection{Increasing Numbers of Non-Human Primates (NHPS)}

There is, therefore, great, well-founded, concern that this interest will translate into greater creation of GM monkeys (e.g. Liu et al., 2014; Niu et al., 2014). Examples of GM primates have already been mentioned (Cyranoski, 2016b; Liu et al., 2016; Sasaki et al., 2009; Snowdon, 2016), following on from, for example, the first reports of GM macaques in 2001 (Chan et al., 2001), and a GM NHP model of Huntington's disease (Yang et al., 2008b). Some scientists are calling for further increases. To illustrate, a 2016 paper lamenting the failure of animal research (including NHPS) to translate to a greater understanding of human brain disorders and their treatment-largely due to "lack of good animal models" and "profound differences in brain and behavior" between humans and nonhumans-puts its weight firmly, and speculatively, behind GM NHPs as a solution (Jennings et al., 2016, p. 1123). Associated suffering is justified by a brief assurance of veterinary oversight and intervention. While accepting that greatly expanding GM NHP creation and use is challenging in many ways, the authors propose a "concerted international effort" to overcome those challenges (Jennings et al., 2016, p. 1128), involving automated methods for training the animals to comply with the researchers' demands, chronic use of intracranial electrodes, and the creation of an international network of NHP centers and vendors. Overall, a horrifying vision for animal advocates, and scientifically unjustifiable in any case. My colleagues (at Cruelty Free International, and indeed in the wider animal protection community) and I agree that there is a "dismal record of drug development for neurological and psychiatric disease over the past several decades" and that "basic neuroscience has failed to deliver substantially new and effective treatments for many brain disorders, partially because the animal modelling was done in species whose brains are too dissimilar from those of humans" (Jennings et al., 2016, p. 1128). However, we believe that modifying a gene or two in these poor models cannot overcome these problems or lead to research that is any less unethical.

GM NHP creation also suffers from the same problems as GM rodents, even 16 years after the first GM monkey was born (Chan et al., 2001); and so, widespread, efficient, successful, generation of human-relevant GM NHPs may be a forlorn hope anyway (Luo, $\mathrm{Li}$ and $\mathrm{Su}, 2016$ ). Surprisingly little analysis had been done of this until recently. Though CRISPR has intensified the generation of GM NHPS, targeting efficiency in NHPS is still low, "successful gene replacement in monkeys via the CRIPSR /Cas9 system remains elusive, possibly due to the complexity of DNA repair mechanisms in monkeys" (Luo et al., 2016, p. 242), and "there are still some technical limitations for its use in non-human primates" (Guo and Li, 2015). A 2017 report acknowledges "the incidence of undesirable outcomes has not been well characterized". It states: "Most studies 
experienced very high rates of developmental arrest (can be 90\%) ... [which] further raises concerns about non-genetic technical factors contributing to low rates of survival" (Midic et al., 2017, p. 4). While this study claimed that the creation of GM NHP embryos could be $80 \%-100 \%$ efficient, this does not reflect on the efficiency of generating otherwise healthy adult N HPs with desired genetic modifications, and without confounding and/or welfare-compromising offtarget effects. The same study suggests that mosaicism (where offspring contain cells with different genes/gene variants) is "substantial" and is "a significant limitation," and accepts that the creation of GM NHPs to date was "achieved at a very high cost in terms of the number of embryos used," due in part to the "very limited (around 10\%) viability of transferred embryos to term" (Midic et al., 2017, p. 15; see also Chen et al., 2015). They conclude that inefficiency remains "a major barrier to practical use of the technology in nonhuman primates" (Midic et al., 2017, p. 15); and that the entire process is financially costly. To illustrate, one effort to generate GM NHPS via CRISPR, with two disrupted genes, reported that of 22 embryos injected, 15 (68\%) survived culturing, while on average just over one third of these contained the desired modification (Niu et al., 2014). Subsequent attempts to generate GM monkeys involved injecting 186 zygotes; 83 ( $45 \%$ ) were transferred to 29 surrogate females, establishing 10 pregnancies (34\%), with 19 fetuses. The paper was published while 8/10 were still pregnant; one miscarried, and the other gave birth to twins, whose genes had been successfully modified, though mosaicism was confirmed, and phenotype had yet to be established.

This is all of particular concern because experimentation on monkeys is opposed much more strongly than on rodents (Aldhous, Coghlan and Copley, 1999; Animal Aid, 2003; Clemence and Leaman, 2016; Leaman, Latter and Clemence, 2014; TNS Opinion \& Social, 2010); and genetic manipulation of "higher" organisms evokes stronger concern from the public (Olsson and Sandøe, 2010). The European Science Foundation's European Medical Research Councils group has stated: "Whether a species needs special protection should not be based solely on its phylogenetic relations to humans, but on its potential for suffering. NHPS are distinguished by the very advanced nature of their social, cognitive, sensory, and motor functions" (Olsson and Sandøe, 2010, p. 185).

\section{Failure of GM Animals and Consequences for Animals} and Humans

Much has been published on the failures of $\mathrm{GM}$ animals to live up to their promise, though criticisms of GM animals are frequently understated, couched, for example, as follows: they do not always accurately reflect the human condition; 
they have limitations; data must be interpreted carefully; and so on. Examples of failures are numerous, and include Parkinson's and Alzheimer's diseases, cystic fibrosis, type I and type II diabetes, amyotrophic lateral sclerosis, Kallmann's syndrome, Lesch-Nyhan's disease, ataxia-telangiectasia, sickle-cell anemia, deafness, visual defects, Duchenne muscular dystrophy, Down's syndrome, and schizophrenia (Pratt et al., 2012), multiple sclerosis, cancers, and immunotherapy (Ruggeri, Camp and Miknyoczki, 2014), migraine (Storer, Supronsinchai and Srikiatkhachorn, 2015), pain (Craig, 2009; Mogil, 2009), and depression (Benatar, 2007; Bhogal and Combes, 2006; Davis, 2008; McGonigle, 2014; Norgren, 2004; Webb, 2014). It is, however, increasingly acknowledged in scientific literature that GM animals are failing to deliver by any measure. For example, GM-based "advances" in animal models of many human conditions and diseases "have not made a significant increase in improving the rate of success in Phase II proofof-concept studies"; in other words, GM animals are not leading to more, better, safer drugs and indeed may well be hindering the process because they are misleading (Hunter, 2011, p. 1). GM-animal models of CNS disorders "have been increasingly criticized in the wake of numerous clinical trial failures of NCES [new chemical entities, or new drugs] with promising preclinical profiles" (McGonigle, 2014, p.140), and they are "criticized for their limited ability to predict NCE efficacy, safety and toxicity in humans" (McGonigle and Ruggeri, 2014, p. 162). Clinical trials of gene therapy for heart failure and muscular dystrophy, despite early promise, have failed (Hulot, Ishikawa and Hajjar, 2016; Lu, Cirak and Partridge, 2014). And despite many years of substantial effort in the field of xenotransplantation, and early promises that successful transplantation of pig organs into humans would be realized by 2010 and worth multiple billions of dollars, the most recent developments claim no more success than a GM pig's heart surviving in a monkey for 51 days (Johnston, 2016), or in the abdomen of a baboon in addition to its own heart for just over two years, until they were rejected when immunosuppressive drugs were reduced (Mohiuddin et al., 2016; Servick, 2016).

Attempts to overcome other significant hurdles continue, such as porcine endogenous retrovirus (PERV) in pigs, which can cause problems in humans (Yang et al., 2015); but there remain persistent issues, such as immune rejection; transmission of infectious agents; ethical problems and boundaries; aspects of physiological compatibility, such as discrepancies in coagulation and metabolism; and others (Niemann and Petersen, 2016). Some argue xenotransplantation is not needed anyway. Prevention of much of the need for transplantation via education and health measures, improved donor recruitment, and mandated choice and presumed consent/opt-out schemes, and others have all had positive outcomes in countries that have adopted them (Perera, Mirza and Elias, 2009). 
With specific regard to CRISPR, there is also evidence to question claims that it can improve matters and facilitate more accurate and human-relevant models. An approach utilizing Morpholino oligomers (MOs) has been widely used to investigate gene function in zebrafish, but attempts to confirm findings for specific genes using CRISPR have been extremely confounding. One study reported that most genes altered by CRISPR failed to show similar phenotypes to experiments that altered the expression of the same genes using Mos, which the authors attributed to differing off-target effects from the techniques (Kok et al., 2015). This is mirrored in a study comparing selected genes affected by CRISPR and a gene-silencing method using short hairpin RNAS (shRNA). These methods were found to have similar precision; but each affected "numerous" genes that the other did not, attributable to differences in off-target effects and in the timing of each (Morgens et al., 2016). To illustrate, a recent study revealed that previous research implicating the MELK gene in certain breast cancers - with sufficient certainty to prompt pharmaceutical companies to develop drugs to block its activity, some of which proceeded to human trialsmay be unreliable. When the MELK gene was knocked out using CRISPR, cancer cells multiplied unexpectedly, and drugs that targeted MELK still stopped their growth. This casts doubt on the role of MELK, and suggests that drugs targeting MELK work through other targets (Lin et al., 2017).

It is often, perfectly reasonably, asked if such failures may be balanced against any successes of GM technology. This is not the purpose of this chapter, which is to highlight issues and caveats with it and to supply a more critical argument against its use. However, any claimed successes, in which it is implied that the use of GM animals has resulted directly in human benefit, must fulfil the following criteria: data from the GM animal experiments must be reliably and sufficiently translatable to humans; these experiments must have provided data that could not have been obtained in any other way; and these data must have been critical to the ultimate human benefit. Even if, for the sake of argument, one assumes such examples exist, they still must be balanced against an objective appraisal of the scale of failure and against the ethical cost of the animal research involved.

\section{Reasons for These Failures}

Reasons proffered for this scale of failure include the evolutionary distance of humans and non-human species-approximately 65 million years for humans and mice-and all consequent differences in gene complement and expression, the artificiality of induced diseases, and the inbred strains of 
animals often used (Davis, 2008). See also two comprehensive reviews of genetic differences between humans and chimpanzees (chimpanzees were used in science in the us until very recently), and humans and monkeys (Bailey, 2011, 2014). Even with current knowledge, limited because such differences have barely been sought, they are much more widespread and extensive, with significant and varied consequences, than is generally accepted. There are significant differences in gene complement, but more importantly, in gene expression, i.e., how these genes are regulated and used in the organism, even where they are common to both species. These differences affect all biological systems, but notably the immune system, the brain, and the liver, which are fundamental to much biomedical research involving infectious agents and disease, autoimmunity and inflammation, neuroscience and neurological diseases, and drug safety and efficacy. It is these differences that underpin the failures of animal research, whether GM or not, discussed in this chapter.

Of course, genetic differences between humans and NHPs, as appreciable as they are, are not as great as those between humans and mice, who constitute the greatest numbers of GM animals used in science. These differences have not yet been elucidated in detail, but illustrative examples exist. For example, a systematic comparison of the mouse and human genomes has revealed that there is significant conservation of functional genes themselves, with around half of human DNA aligning with mouse DNA when directly compared; however, this of course means that half of it does not. Furthermore, there are, crucially, "wide ranging differences" in many biological pathways and cellular functions, which show "considerable divergence"; and the areas of the genome that control and regulate gene expression are substantially different (Yue et al., 2014, p. 355). Indeed, many disease-causing mutations are in these areas, rather than in the main protein-coding parts of genes themselves. Because these differ, particularly between species, this can make direct animal-human comparisons not just difficult and uncertain, but impossible (Bassett, 2017). Even when humans and mice share genes, they can show functional differences: a study of 120 genes that are known to be essential for life in humans, revealed that almost one quarter of them are not essential for life in mice (Liao and Zhang, 2008).

The problem with a shift toward GM NHPs, in the hope of greater human relevance, is that there is little or no evidence to support this, even if NHPS are evolutionarily less removed from humans. While it is true to some extent that N H PS "are genetically and phenotypically closer to humans, particularly in regards to anatomy, physiology, cognition, and gene sequences," it does not follow that they are, therefore, "optimal animal models for genetic modification in an attempt to understand human biology" (Luo et al., 2016, p. 241,). This is 
only valid if this results in better translation of NHP data to human benefit. I argue that it does not, because there is simply no evidence that it does.

One positive for animal advocates, while reading myriad literature on the burgeoning creation of GM animals, is that there now appears to be more honesty about, and criticism of, the human relevance of non-GM animals. A paper in the prestigious journal, Nature, cited the wholesale failure of new drugs to treat amyotrophic lateral sclerosis (ALS), a fatal neurodegenerative condition, known as Lou Gehrig's or motor neuron disease, despite success in animal models of the disease, as well as similar failures in Alzheimer's and cancer, among others (Perrin, 2014). Contemporary criticisms of animal research are welcome because they have been scant from the scientific community for decades. Ironically, many criticisms are akin to those made by animal advocates for many years, which were roundly dismissed. What seems commonplace, however, is the unfortunate and groundless assertion that genetic modification will instantly make failed animal models more human relevant. Evidence suggests otherwise.

Alternatives to GM Animals-The Way Forward

If not GM animals, what is the way forward to understand the myriad human diseases and realize treatments and cures for them? Modeling human diseases in cultured human stem cells continues to take great leaps forward and will surely become a mainstay of biomedical research that "could rival the use of GM mice in popularity" (Musunuru, 2013. p. 901). Somatic cells (cells from various parts of the body, other than reproductive cells, such as sperm and eggs, often skin biopsies or blood) can now be reprogrammed to act as cells in early-stage embryos, able to develop into many different specialized cell types (Takahashi et al., 2007; Takahashi and Yamanaka, 2006). Immense collaborative efforts now collect and characterize cells from many thousands of healthy and diseased human individuals, many with a wide variety of disorders, and use these induced pluripotent stem cells (iPSCs) for comparative studies of normal and diseased states and screening of potential new drugs and therapies, including the study of polygenic disorders (diseases involving many genes). The development of $3 \mathrm{D}$ cell cultures and organoids (cultured miniature organs) is likely to increase the in vivo relevance of this approach, with more faithful and accurate cellular phenotypes (see Bassett, 2017). Organoids successfully developed to date include, brain, intestine, stomach, salivary gland, esophagus, pancreas, liver, breast, lung, prostate, fallopian tube, and taste bud (see Driehuis and Clevers, 2017). Genetically modifying such iPSCs and organoids adds another level 
of sophistication, allowing potential causative gene variants or mutations to be introduced for further study, for example, to validate mutations implicated in causing disease and/or for attempts at repairing faulty genes.

Cell lines for these studies have been generated for many diseases, including Parkinson's, Alzheimer's, Huntington disease, various immune disorders, cardiomyopathy, and cystic fibrosis (Brookhouser et al., 2017; Nishizaki and Boyle, 2017); and efforts at repairing mutated genes in these systems have been promising in, for example, cystic fibrosis and cancers (Driehuis and Clevers, 2017), and retinopathies (Quinn, Pellissier and Wijnholds, 2017). The combined use of genome editing and ipscs offers the ability to study genes and mutations in different human genetic backgrounds, which is especially important for the study of complex neurological disorders. This approach has been found to "closely mimic cellular and molecular features of human diseases." (Heidenreich and Zhang, 2016, p. 42) CRISPR has also aided the derivation of retinal ganglion cells from human PSCs, to model human optic nerves in vitro for research into optic nerve disease (Sluch et al., 2015). The very high efficiency of these types of methods, coupled with the relative ease and speed of the process, and the ability to use and screen many thousands of cell lines in parallel, means that this type of approach to understanding the basis of human disease and to identify therapeutic targets and therapies must be the way forward, in place of creating GM animals (see Bassett, 2017). While the aforementioned off-target effects are a confounding factor, they matter much less in cell lines than in animals, because there are no ethical problems; and cell lines can be produced, screened, and evaluated much more quickly and efficiently.

\section{8}

\section{Summary}

Acknowledgement of the suffering of GM animals has, at least, led to some efforts to reduce it, even if these have not, to date, led to overall reductions in their creation and experimental use. Guidelines for the use and care of GM animals, for example, are welcome. Working Groups and international guidelines have been commissioned to this end (Wells et al., 2006) and are at least intended to reduce the number of GM animals created and improve the welfare of those who are. These include requiring attempts to establish the appropriateness of generating any GM animal, both scientifically and with regard to welfare, involving a harm-benefit analysis; and a stipulation that new animals should not be generated if similar suitable lines already exist, and/ or if an in vitro method could be used instead (Rose et al., 2013). These guidelines need to be widely adopted and enforced, but also greater training of staff 
responsible for care, for example, can only make little or no impact on the welfare of the many millions of $\mathrm{GM}$ animals that will end up in laboratories worldwide. Ultimately, guidelines or not, GM animals suffer greatly, in their tens of millions each year. Controversially, one developing effort to address this, already attempted in rats, is to make GM animals who-while still able to sense pain-are incapable of finding its sensation unpleasant (Shriver, 2015).

Yet, the public demands that such pain and suffering is avoided or controlled at all costs for them to accept animal research, GM or not (Aldhous et al., 1999; Animal Aid, 2003; Clemence and Leaman, 2016; Leaman, Latter and Clemence, 2014; TNS Opinion \& Social, 2010). Generally, people are much less accepting of GM animals than they are of GM plants and GM food compared to other GM applications. While perceptions of risk are offset by perceived benefits (Frewer et al., 2013), there is evidence that the EU populace has in the past "morally rejected genetic engineering of animal models of disease," which is incompatible with the direction in which worldwide attitudes and laws are moving (Rollin, 2015, p. 114). Utilitarians may argue that human benefit outweighs this pain and suffering. But, given the degree of animal pain and suffering involved, both qualitatively and quantitatively, the relatively small number of people who stand to benefit from any breakthrough for many of the rare genetic diseases that may be modelled, and how unlikely GM animals are to contribute to breakthroughs given the burgeoning evidence against them, how can this be so? This is especially true if any harm-benefit analyses applied to license applications for animal experimentation are conducted properly and more stringently, as there are calls for authorities to ensure (Würbel, 2017).

Even if one presumes sufficient human benefit from research on GM animals, which I (and many others) believe is not supported by evidence, there remain serious scientific issues with, and ethical/welfare consequences of, genetic engineering. Despite the best currently available method of CRISPR having "swept through labs around the world" recently, and being touted as a "revolution" (Ledford, 2015, pp. 20-21), it is still considered as being "in an immature phase of development" and "not yet ready for therapeutic applications in humans given the low editing efficiency" ( $<15 \%)$ (D'Agostino and D'Aniello, 2017 , p. 4). This is also due to the persistent concerns over the stubborn nature of off-target mutations, occurring at frequencies of up to $60 \%$, more than the best efficiency of intended on-target modifications. Even if off-target issues can be greatly reduced, which is questionable, they are still of concern clinically, as "Even low-frequency events could potentially be dangerous if they accelerate a cell's growth and lead to cancer" (Ledford, 2015, p. 22). 
The efficiency of CRISPR translation to clinical applications is also of concern. Scientists using CRISPR to correct a disease-causing mutation in mice in a gene therapy experiment had to "pump large volumes of liquid into blood vessels - something that is not generally considered feasible in people" and this corrected the mutation in just $0.4 \%$ of the mice's cells, not enough to be effective (Ledford, 2015, p. 21). Delivery methods for introducing the CRISPR apparatus to cells also need optimizing (Peng, Lin and Li, 2016). Carrier DNA used to introduce CRISPR to target cells may become integrated into the host genome, causing off-target effects, which may disrupt the genome editing process and can cause toxicity. Alternative methods may be stressful to cells, altering gene expression, or leading to high off-target effects (Peng, Lin and Li, 2016). Despite these concerns, the first clinical trial involving CRISPR commenced in October 2016, when knockout immune cells were injected into patients as potential therapy for metastatic non-small cell lung cancer (Cyranoski, 2016a); and now CRISPR is already part of ten clinical trials just a few years after it became mainstream (clinicaltrials.gov). It remains to be seen if they will be successful, and if so, how much they rely on GM animal research.

\section{Conclusion}

GM animal creation and experimentation takes the lives of tens of millions of animals each year and involves considerable suffering at every stage. Its scientific value is extremely poor, to the point of it being unnecessary, misleading and therefore harmful not just to the animals involved, but also to people, who depend on good science to understand, treat, and cure the diseases that affect us all. The continued insistence of many who practice and fund GM research that animals must be used is without foundation. Non-human animals have always been bad models for humans due to species differences, and no amount of genetic modification can remedy that, even if it were perfect. GM processes are far from perfect, however. Even the best is extremely inefficient, and confounded not just by those species differences, but also by off-target effects of the GM process. These issues are at the root of animal research failing to be relevant and reliable for humans, of animals being poor models for disease right across the spectrum, and of the failure of $90 \%-95 \%$ of new drugs in human trials that were successful in animal tests (Bailey, Thew and Balls, 2013; Bailey, Thew and Balls, 2014; Bailey, Thew and Balls, 2015). Moving away from animal research, including the use of GM animals, has never been more imperative. 


\section{References}

Albadri, S., F. Del Bene and C. Revenu (2017). Genome Editing Using CRISPR/Cas9based Knock-in Approaches in Zebrafish. Methods, 121, pp. 77-85.

Aldhous, P., A. Coghlan and J. Copley (1999). Animal Experiments: Where Do You Draw the Line? Let the People Speak. New Scientist, 162(2187), pp. 26-31.

Animal Aid (2003). Public Says "no" to Primate Research. [online] Available at: https:// web.archive.org/web/20160812204605/http://animalaid.org.uk/h/n/NEWS/news _experiments/ALL/136// [Accessed 30 July 2018].

Bailey, J. (2011). Lessons from Chimpanzee-based Research on Human Disease: The Implications of Genetic Differences. Alternatives to Laboratory Animals, 39(6), pp. 527-540.

Bailey, J. (2014). Monkey-based Research on Human Disease: The Implications of Genetic Differences. Alternatives to Laboratory Animals, 42, pp. 287-317.

Bailey, J., M. Thew and M. Balls (2013). An Analysis of the Use of dogs in Predicting Human Toxicology and Drug Safety. Alternatives to Laboratory Animals, 41, pp. 335-350.

Bailey, J., M. Thew and M. Balls (2014). An Analysis of the Use of Animal Models in Predicting Human Toxicology and Drug Safety. Alternatives to Laboratory Animals, 42, pp. 189-199.

Bailey, J., M. Thew and M. Balls (2015). Predicting Human Drug Toxicity and Safety Via Animal Tests: Can Any One Species Predict Drug Toxicity in Any Other, and Do Monkeys Help? Alternatives to Laboratory Animals, 43, pp. 393-403.

Bassett, A.R. (2017). Editing the Genome of hiPSC with CRISPR/Cas9: Disease Models. Mammalian Genome, [Epub ahead of print], pp. 1-17.

Baud, A. and J. Flint (2017). Identifying Genes for Neurobehavioural Traits in Rodents: Progress and Pitfalls. Disease Models and Mechanisms, 10(4), pp. 373-383.

Bayat, H., M. Omidi, M. Rajabibazl, S. Sabri and A. Rahimpour (2017). The CRISPR growth Spurt: From Bench to Clinic on Versatile Small RNAs. Journal of Microbiology and Biotechnology, 27(2), pp. 207-218.

Benatar, M. (2007). Lost in Translation: Treatment Trials in the SOD1 Mouse and in Human ALS. Neurobiology of Disease, 26(1), pp. 1-13.

Bhogal, N. and R. Combes (2006). The Relevance of Genetically Altered Mouse Models of Human Disease. Alternatives to Laboratory Animals, 34(4), pp. 429-454.

Bisaria, N., I. Jarmoskaite and D. Herschlag (2017). Lessons from Enzyme Kinetics Reveal Specificity Principles for RNA-guided Nucleases in RNA Interference and CRISPR-based Genome Editing. Cell Systems, 4(1), pp. 21-29.

Bolukbasi, M.F., A. Gupta and S.A. Wolfe (2016). Creating and Evaluating Accurate CRISPR-Cas9 Scalpels for Genomic Surgery. Nature Methods, 13(1), pp. 41-50.

Bortesi, L., C. Zhu, J. Zischewski, L. Perez, L. Bassié, R. Nadi, G. Forni, S.B. Lade, E. Soto, X. Jin, V. Medina, G. Villorbina, P. Muñoz, G. Farré, R. Fischer, R.M. Twyman, 
T. Capell, P. Christou and S. Schillberg (2016). Patterns of CRISPR/Cas9 Activity in Plants, Animals and Microbes. Plant Biotechnology Journal, 14(12), pp. 2203-2216.

Boyd Group (1999). Genetic Engineering: Animal Welfare and Ethics. A Discussion Paper. [online] Available at: https://web.archive.org/web/20070714154044fw_/http://www .boyd-group.demon.co.uk/genmod.htm [Accessed: 30 July 2018].

Brookhouser, N., S. Raman, C. Potts and D.A. Brafman (2017). May I Cut In? Gene Editing Approaches in Human Induced Pluripotent Stem Cells. Cells, 6(1), p. 5 .

Brown, K.V. (2018). The Scientists Who Sparked CRISPR Panic Couldn't Reproduce Their Study Results. [online] Available at: https://gizmodo.com/the-scientists-who -sparked-crispr-panic-couldnt-reprodu-1824181703 [Accessed: 30 July 2018].

Bundesamt für Veterinärwesen (2006). Statistik der Tierversuche in der Schweiz 2005. [online] Available at: https://www.admin.ch/gov/de/start/dokumentation/ medienmitteilungen.msg-id-5911.html [Accessed: 8 August 2017].

Camara, D., I. Dimitrova, M. Doynova, L. Jachacz, D. Kachakova, M. Kepka, C.B. Ould Isselmou, J.P. Vorniere and T. Yungarva (2008). Transgenic and Cloned Animals: Ethical Problems? EU Socrates Erasmus European Community. Agro Campus Ouest.p. 20 [online] Available at: http://bioethics.agrocampus-ouest.eu/infoglueDeliverLive/ digitalAssets/74558_transgenic_r.pdf [Accessed: 30 July 2018].

Caplan, A.L., B. Parent, M. Shen and C. Plunkett (2015). No Time to Waste. The Ethical Challenges Created by CRISPR: CRISPR/Cas, Being an Efficient, Simple, and Cheap Technology to Edit the Genome of any Organism, Raises Many Ethical and Regulatory Issues Beyond the Use to MANIPULATE HUMAN GERM LINE CELLS. EMBO Reports, 16(11), pp. 1421-1426.

Carlson, D.F., C.A. Lancto, B. Zang, E.S. Kim, M. Walton, D. Oldeschulte, C. Seabury, T.S. Sonstegard and S.C. Fahrenkrug (2016). Production of Hornless Dairy Cattle from Genome-edited Cell Lines. Nature Biotechnology, 34(5), pp. 479-481.

Carlson, D.F., W. Tan, S.G. Lillico, D. Stverakova, C. Proudfoot, M. Christian, D.F. Voytas, C.R. Long, C.B. Whitelaw and S.C. Fahrenkrug (2012). Efficient Talen-mediated Gene Knockout in Livestock. Proceedings of the National Academy of Sciences of the United States of America, 109(43), pp. 17382-17387.

Carroll, D. (2018). p53 Throws CRISPR a Curve. Trends in Pharmacological Sciences 39, pp. $783-784$.

Chan, A.W., K.Y. Chong, C. Martinovich, C. Simerly and G. Schatten (2001). Transgenic monkeys Produced by Retroviral Gene Transfer into Mature Oocytes. Science, 291(5502), pp. 309-312.

Chandrasekaran, A.P., M. Song and S. Ramakrishna (2017). Genome Editing: A Robust Technology for Human Stem Cells. Cellular and Molecular Life Sciences, 74(18), pp. $3335-3346$.

Charlesworth, C.T., P.S. Deshpande, D.P. Dever, B. Dejene, N. Gomez-Ospina, S. Mantri, M. Pavel-Dinu, J. Camarena, K.I. Weinberg and M.H. Porteus (2018). Identification 
of Pre-Existing Adaptive Immunity to Casg Proteins in Humans. bioRxiv. Preprint. doi.org/10.1101/243345.

Chen, R.J., G. Kelly, A. Sengupta, W. Heydendael, B. Nicholas, S. Beltrami, S. Luz, L. Peixoto, T. Abel and S. Bhatnagar (2015). Micrornas as Biomarkers of Resilience or Vulnerability to Stress. Neuroscience, 305, pp. 36-48.

Cho, S.W., S. Kim, Y. Kim, J. Kweon, H.S. Kim, S. Bae and J.S. Kim (2014). Analysis of Offtarget Effects of CRISPR/Cas-derived RNA-guided Endonucleases and Nickases. Genome Research, 24(1), pp. 132-141.

Clemence, M. and J. Leaman (2016). Public Attitudes to Animal Research in 2016. A report by Ipsos MORI for the Department for Business, Energy \& Industrial Strategy, Ipsos MORI Social Research Instititute. [online] Available at: https://www .ipsos.com/sites/default/files/publication/1970-01/sri-public-attitudes-to-anima l-research-2016.pdf [Accessed 30 July 2018].

Combes, R.D. and M. Balls (2014). Every Silver Lining Has a Cloud: The Scientific and Animal Welfare Issues Surrounding a New Approach to the Production of Transgenic Animals. Alternatives to Laboratory Animals, 42(2), pp. 137-145.

Connor, S. (2015). Genetically Modified Salmon Becomes First to Be Approved for Human Consumption - But It Won't Have to Be Labelled as G M. The Independent. [online] Available at: http://www.independent.co.uk/news/science/genetically -modified-sa.approved-for-human-consumption-but-it-wont-have-to-a6741031 .html [Accessed: 30 July 2018].

Cornu, T.I., C. Mussolino and T. Cathomen (2017). Refining Strategies to Translate Genome Editing to the Clinic. Nature Medicine, 23(4), pp. 415-423.

Cradick, T.J., E.J. Fine, C.J. Antico and G. Bao (2013). CRISPR/Cas9 Systems Targeting $\beta$-globin and $\mathrm{CCR}_{5}$ Genes Have Substantial Off-target Activity. Nucleic Acids Research, 41(20), pp. 9584-9592.

Craig, A.D. (2009). A Rat Is Not a Monkey Is Not a Human: Comment on Mogil. Nature Reviews Neuroscience, 10(6), p. 466.

Cyranoski, D. (2015). Super-muscly Pigs Created by Small Genetic Tweak. Nature, 523(7558), pp. 13-14.

Cyranoski, D. (2016a). Crispr Gene-editing Tested in a Person for the First Time. Nature, $539(7630)$, p. 479.

Cyranoski, D. (2016b). Monkeys Genetically Modified to Show Autism Symptoms. Nature, $5^{29}\left(75^{87}\right)$, p. 449 .

D’Agostino, Y. and S. D'Aniello (2017). Molecular Basis, Applications and Challenges of CRISPR/Cas9: A Continuously Evolving Tool for Genome Editing. Briefings in Functional Genomics, 16(4), pp. 211-216.

Davis, M.M. (2008). A Prescription for Human Immunology. Immunity, 29(6), pp. $835^{-838 .}$ 
Dennis, M.B. (2002). Welfare Issues of Genetically Modified Animals. Institute for Laboratory Animal Research Journal, 43(2), pp. 100-109.

Di Leonardo, A., S.P. Linke, K. Clarkin and G.M. Wahl (1994). DNA damage triggers a prolonged p53-dependent G1 arrest and long-term induction of Cip1 in normal human fibroblasts. Genes and Development, 8, pp. 2540-2551.

Ding, Y., H. Li, L.L. Chen and K. Xie (2016). Recent Advances in Genome Editing Using CRISPR/Cas9. Frontiers in Plant Science, 7, p. 703.

Doane, S. (2016). China Building Bigger, Strong Beagles Through Genetics. CBS News. [online] Available at: http://www.cbsnews.com/news/genetic-modifying-of-beagles -a-controversial-practice-in-china/ [Accessed: 30 July 2018].

Doerflinger, M., W. Forsyth, G. Ebert, M. Pellegrini and M.J. Herold (2017). CRISPR/ Cas9, The Ultimate Weapon to Battle Infectious Diseases. Cellular Microbiology, 19(2), Epub 2016 Dec 6.

Driehuis, E. and H. Clevers (2017). CRISPR/Cas 9 Genome Editing and Its Applications in Organoids. American Journal of Physiology, Gastrointestinal and Liver Physiology, 312(3), pp. G257-G265.

Editorial (2018). CRISPR Off-targets: A Reassessment. Nature Methods 15, pp. 229-229. Fellmann, C., B.G. Gowen, P.C. Lin, J.A. Doudna and J.E. Corn (2017). Cornerstones of CRISPR-Cas in Drug Discovery and Therapy. Nature Reviews. Drug Discovery, 16(2), pp. 89-100.

Ferrarelli, L.K. (2018). CRISPR, cancer, and p53. Science Signalling, 11(539), p. eaau7344. Fineran, P.C. and E. Charpentier (2012). Memory of Viral Infections by Crispr-Cas Adaptive Immune Systems: Acquisition of New Information. Virology, 434(2), pp. 202-209.

Foronda, M. and L.E. Dow (2018). CRISPR: Stressed about p53. Trends in Molecular Medicine, 24, pp. 731-733.

Frewer, L.J., G.A. Kleter, M. Brennan, D. Coles, A.R. Fischer, L.M. Houdebine, C. Mora, K. Millar and B. Salter (2013). Genetically Modified Animals from Life-science, Socioeconomic, and Ethical Perspectives: Examining Issues in an EU Policy Context. $\mathrm{Na}$ ture Biotechnology, 30(5), pp. 447-46o.

Fu, Y., J.A. Foden, C. Khayter, M.L. Maeder, D. Reyon, J.K. Joung and J.D. Sander (2013). High-frequency Off-target Mutagenesis Induced by CRISPR-Cas Nucleases in $\mathrm{Hu}-$ man Cells. Nature Biotechnology, 31(9), pp. 822-826.

Guernet, A. and L. Grumolato (2017). CRISPR/Cas9 Editing of the Genome for Cancer Modeling. Methods, 121-122, pp. 130-137.

Guha, T.K., A. Wai and G. Hausner (2017). Programmable Genome Editing Tools and Their Regulation for Efficient Genome Engineering. Computational and Structural Biotechnology Journal, 15, pp. 146-16o.

Guo, X. and X.J. Li (2015). Targeted Genome Editing in Primate Embryos. Cell Research, 25(7), pp. $767-768$. 
Guo, Y., H. Li, Y. Wang, X. Yan, X. Sheng, D. Chang, X. Qi, X. Wang, Y. Liu, J. Li and H. Ni (2017). Screening Somatic Cell Nuclear Transfer Parameters for Generation of Transgenic Cloned Cattle with Intragenomic Integration of Additional Gene Copies That Encode Bovine Adipocyte-type Fatty Acid-binding Protein (a-fabp). Molecular Biology Reports, 44(1), pp. 159-168.

Haapaniemi, E., S. Botla, J. Persson, B. Schmierer and J. Taipale (2018). CRISPR-Cas9 genome editing induces a p53mediated DNA damage response. Nature Medicine 24, pp. 927-930.

Hai, T., F. Teng, R. Guo, W. Li and Q. Zhou (2014). One-step Generation of Knockout Pigs by Zygote Injection of CRISPR/Cas System. Cell Research, 24(3), pp. 372-375.

Hawkins, P., D.B. Morton, O. Burman, N. Dennison, P. Honess, M. Jennings, S. Lane, V. Middleton, J.V. Roughan, S. Wells, K. Westwood and UK Joint Working Group on Refinement (BVAAWF). (2011). A Guide to Defining and Implementing Protocols for the Welfare Assessment of Laboratory Animals. Eleventh report of the BVAAWF/FRAME/RSPCA/UFAW Joint Working Group on Refinement. Laboratory Animals, 45(1), pp. 1-13.

Heidenreich, M. and F. Zhang (2016). Applications of CRISPR-Cas Systems in Neuroscience. Nature Reviews Neuroscience, 17(1), pp. 36-44.

Hendriksen, C. and H. Spielmann (2014). New Techniques for Producing Transgenic Animals - A Mixed Blessing from both the Scientific and Animal Welfare Perspectives. Alternatives to Laboratory Animals, 42(2), pp. 93-94.

High Level Panel of Experts on Food Security and Nutrition (2014). Food Losses and Waste in the Context of Sustainable Food Systems. [online] Available at: http://www .fao.org/3/a-i39o1e.pdf [Accessed 30 July 2018].

Hockemeyer, D. and R. Jaenisch (2016). Induced Pluripotent Stem Cells Meet Genome Editing. Cell Stem Cell, 18, pp. 573-586.

Hollstein, M., D. Sidransky, B. Vogelstein and C.C. Harris (1991). p53 mutations in human cancers. Science, 253, pp. 49-53.

Hong, S.G., M.K. Kim, G. Jang, H.J. Oh, J.E. Park, J.T. Kang, O.J. Koo, T. Kim, M.S. Kwon, B.C. Koo, J.C. Ra, D.Y. Kim, C. Ko and B.C. Lee (2009). Generation of Red Fluorescent Protein Transgenic Dogs. Genesis, 47(5), pp. 314-322.

Hsu, P.D., E.S. Lander and F. Zhang (2014). Development and Applications of CRISPRCas9 for Genome Engineering. Cell, 157(6), pp. 1262-1278.

Hsu, P.D., D.A. Scott, J.A. Weinstein, F.A. Ran, S. Konermann, V. Agarwala, Y. Li, E.J. Fine, X. Wu, O. Shalem, T.J. Cradick, L.A. Marraffini, G. Bao and F. Zhang (2013). DNA Targeting Specificity of RNA-guided Cas9 Nucleases. Nature Biotechnology, 31(9), pp. $827-832$.

Huang, Z., A. Tomitaka, A. Raymond and M. Nair (2017). Current Application of CRISPR/Cas9 Gene-editing Technique to Eradication of HIV/AIDS. Gene Therapy, 24(7), pp. 377-384. 
Hubrecht, R. (1995). Genetically Modified Animals, Welfare and U K Legislation. Animal Welfare, 4, pp. 163-170.

Hulot, J.S., K. Ishikawa and R.J. Hajjar (2016). Gene Therapy for the Treatment of Heart Failure: Promise Postponed. European Heart Journal, 37(21), pp. 1651-1658.

Hunter, A.J. (2011). Have Animal Models of Disease Helped or Hindered the Drug Discovery Process?. Annals of the New York Academy of Sciences, 1245, pp. 1-2.

Ihry, R.J., K.A.Worringer, M.R. Salick, E. Frias, D.Ho, K. Theriault,S. Kommineni,J.Chen, M. Sondey, C. Ye, R. Randhawa, T. Kulkarni,Z. Yang, G. McAllister, C. Russ, J. Reece-Hoyes, W. Forrester, G.R. Hoffman, R. Dolmetsch and A. Kaykas (2018). p53 inhibits CRISPRCas9 engineering in human pluripotent stem cells. Nature Medicine, 24, pp.939-946.

Jaenisch, R. and B. Mintz (1974). Simian Virus 40 DNA Sequences in DNA of Healthy Adult Mice Derived from Preimplantation Blastocysts Injected with Viral DNA. Proceedings of the National Academy of Sciences of the United States of America, 71(4), pp. 1250-1254.

Jennings, C.G., R. Landman, Y. Zhou, J. Sharma, J. Hyman, J.A. Movshon, Z. Qiu, A.C. Roberts, A.W. Roe, X. Wang, H. Zhou, L. Wang, F. Zhang, R. Desimone and G. Feng (2016). Opportunities and Challenges in Modeling Human Brain Disorders in Transgenic Primates. Nature Neuroscience, 19(9), pp. 1123-1130.

Jiang, F. and J.A. Doudna (2017). CRISPR-Cas9 Structures and Mechanisms. Annual Review of Biophysics, 46, pp. 505-529.

Johnston, I. (2016). Transplanted Pig's Heart Survives in Monkey for at least $5^{1}$ Days in New Record. The Independent. [online] Available at: http://www.independent. co.uk/news/science/pig-heart-monkey-51-days-survival-transplant-a7420446.html [Accessed: 30 July 2018].

Kanchiswamy, C.N., M. Maffei, M. Malnoy, R. Velasco and J.S. Kim (2016). Fine-tuning Next-generation Genome Editing Tools. Trends in Biotechnology, 34(7), pp. 562-574.

Karolinska Institutet (2018). Press release: Genome-editing tool could increase cancer risk. Available: https://ki.se/en/news/genome-editing-tool-could-increase-cancer -risk [Accessed 13 Sep 2018].

Kim, H.J., H.J. Lee, H. Kim, S.W. Cho and J.S. Kim (2009). Targeted Genome Editing in Human Cells with Zinc Finger Nucleases Constructed Via Modular Assembly. Genome Research, 19(7), pp. 1279-1288.

Kleinstiver, B.P., V. Pattanayak, M.S. Prew, S.Q. Tsai, N.T. Nguyen, Z. Zheng and J.K. Joung (2016). High-fidelity CRISPR-Cas9 Nucleases with No Detectable Genomewide Off-target Effects. Nature, 529(7587), pp. 490-495.

Kok, F.O., M. Shin, C.W. Ni, A. Gupta, A.S. Grosse, A. van Impel, B.C. Kirchmaier, J. Peterson-Maduro, G. Kourkoulis, I. Male, D.F. DeSantis, S. Sheppard-Tindell, L. Ebarasi, C. Betsholtz, S. Schulte-Merker, S.A. Wolfe and N.D. Lawson (2015). Reverse Genetic Screening Reveals Poor Correlation Between Morpholino-induced and Mutant Phenotypes in Zebrafish. Developmental Cell, 32(1), pp. 97-108. 
Komor, A.C., A.H. Badran and D.R. Liu (2017). CRISPR-based Technologies for the Manipulation of Eukaryotic Genomes. Cell, 168(1-2), pp. 20-36.

Koscielny, G., G. Yaikhom, V. Iyer, T.F. Meehan, H. Morgan, J. Atienza-Herrero, A. Blake, C.K. Chen, R. Easty, A. Di Fenza, T. Fiegel, M. Grifiths, A. Horne, N.A. Karp, N. Kurbatova, J.C. Mason, P. Matthews, D.J. Oakley, A. Qazi, J. Regnart, A. Retha, L.A. Santos, D.J. Sneddon, J. Warren, H. Westerberg, R.J. Wilson, D.G. Melvin, D. Smedley, S.D. Brown, P. Flicek, W.C. Skarnes, A.M. Mallon and H. Parkinson (2014). The International Mouse Phenotyping Consortium Web Portal, A Unified Point of Access for Knockout Mice and Related Phenotyping Data. Nucleic Acids Research, 42(Database issue), pp. D802-9.

Kosicki, M., K. Tomberg and A. Bradley (2018). Repair of double-strand breaks induced by CRISPR-Casg leads to large deletions and complex rearrangements. Nature Biotechnology, [Epub ahead of print].

Laboratory Animal Science Association (2008). Transgenics. Position paper. [online] Available: http://www.lasa.co.uk/pdf/position_transgenics.pdf [Accessed 30 July 2018], p. 4.

Lai, L., J.X. Kang, R. Li, J. Wang, W.T. Witt, H.Y. Yong, Y. Hao, D.M. Wax, C.N. Murphy, A. Rieke, M. Samuel, M.L. Linville, S.W. Korte, R.W. Evans, T.E. Starzl, R.S. Prather and Y. Dai (2006). Generation of Cloned Transgenic Pigs Rich in Omega-3 Fatty Acids. Nature Biotechnology, 24(4), pp. 435-436.

Leaman, J., J. Latter and M. Clemence (2014). Attitudes to Animal Research in 2014. A report by Ipsos MORI for the Department for Business Innovation \& Skills. Ipsos MORI Social Research Institute. [online] Available at: https://www.ipsos.com/ sites/default/files/migrations/en-uk/files/Assets/Docs/Polls/sri_BISanimalresearch _NONTRENDreport.pdf [Accessed 30 July 2018].

Ledford, H. (2015). CRISPR, The Disruptor. Nature, 522(7554), pp. 20-24.

Li, H., C. Sheng, S. Wang, L. Yang, Y. Liang, Y. Huang, H. Liu, P. Li, C. Yang, X. Yang, L. Jia, J. Xie, L. Wang, R. Hao, X. Du, D. Xu, J. Zhou, M. Li, Y. Sun, Y. Tong, Q. Li, S. Qiu and H. Song (2017). Removal of Integrated Hepatitis B Virus DNA Using CRISPR-Casg. Frontiers in Cellular and Infection Microbiology, 7, p. 91.

Liang, P., Y. Xu, X. Zhang, C. Ding, R. Huang, Z. Zhang, J. Lv, X. Xie, Y. Chen, Y. Li, Y. Sun, Y. Bai, Z. Songyang, W. Ma, C. Zhou and J. Huang (2015). CRISPR/Cas9-mediated Gene Editing in Human Tripronuclear Zygotes. Protein and Cell, 6(5), pp. 363-372.

Liao, B.Y. and J. Zhang (2008). Null Mutations in Human and Mouse Orthologs Frequently Result in Different Phenotypes. Proceedings of the National Academy of Sciences of the United States of America, 105(19), pp. 6987-6992.

Lin, A., C.J. Giuliano, N.M. Sayles and J.M. Sheltzer (2017). CRISPR/Cas9 Mutagenesis Invalidates a Putative Cancer Dependency Targeted in On-going Clinical Trials. eLife, 6, p. e24179. 
Liu, H., Y. Chen, Y. Niu, K. Zhang, Y. Kang, W. Ge, X. Liu, E. Zhao, C. Wang, S. Lin, B. Jing, C. Si, Q. Lin, X. Chen, H. Lin, X. Pu, Y. Wang, B. Qin, F. Wang, H. Wang, W. Si, J. Zhou, T. Tan, T. Li, S. Ji, Z. Xue, Y. Luo, L. Cheng, Q. Zhou, S. Li, Y.E. Sun and W. Ji (2014). TALEN-mediated Gene Mutagenesis in Rhesus and Cynomolgus Monkeys. Cell Stem Cell, 14(3), pp. 323-328.

Liu, Z., X. Li, J.T. Zhang, Y.J. Cai, T.L. Cheng, C. Cheng, Y. Wang, C.C. Zhang, Y.H. Nie, Z.F. Chen, W.J. Bian, L. Zhang, J. Xiao, B. Lu, Y.F. Zhang, X.D. Zhang, X. Sang, J.J. Wu, X. Xu, Z.Q. Xiong, F. Zhang, X. Yu, N. Gong, W.H. Zhou, Q. Sun and Z. Qiu (2016). Autismlike Behaviours and Germline Transmission in Transgenic Monkeys Overexpressing MeCP 2. Nature, 530(7588), pp. 98-102.

Loria, K. (2016). Cows with Horns May Soon Be a Relic of Farming's Painful Past. Business Insider. [online] Available at: http://uk.businessinsider.com/recombinetics -genetically-edited-cattle-without-horns-2016-5?r=us\&ir=t [Accessed: 30 July 2018].

Lu, Q.L., S. Cirak and T. Partridge (2014). What Can We Learn from Clinical Trials of Exon Skipping for DMD. Molecular Therapy, Nucleic Acids, 3, p. e152.

Luo, J., Z. Song, S. Yu, D. Cui, B. Wang, F. Ding, S. Li, Y. Dai and N. Li (2014). Efficient Generation of Myostatin (MSTN) Biallelic Mutations in Cattle Using Zinc Finger Nucleases. PLoS One, 9(4), p. e95225.

Luo, X., M. Li and B. Su (2016). Application of the Genome Editing Tool CRISPR/Cas9 in Non-human Primates. Dongwuxue Yanjiu, 37(4), pp. 214-219.

Lv, Q., L. Yuan, J. Deng, M. Chen, Y. Wang, J. Zeng, Z. Li and L. Lai (2016). Efficient Generation of Myostatin Gene Mutated Rabbit by CRISPR/Cas9. Scientific Reports, 6, p. 25029 .

MarketsandMarkets (2017). Genome Editing/Genome Engineering Market by Technology (CRISPR, TALEN, ZFN), Application (Cell Line Engineering, Animal Genetic Engineering, Plant Genetic Engineering), End User (Biotechnology \& Pharmaceutical Companies, CROs) - Global Forecast 2022. [online] Available at: https://www .marketsandmarkets.com/Market-Reports/genome-editing-engineering-market -23103700o.html [Accessed: 3o July 2018].

McGonigle, P. (2014). Animal Models of CNS disorders. Biochemical Pharmacology, 87(1), pp. 140-149.

McGonigle, P. and B. Ruggeri (2014). Animal Models of Human Disease: Challenges in Enabling Translation. Biochemical Pharmacology, 87(1), pp. 162-171.

Mepham, T.B., R.D. Combes, M. Balls, O. Barbieri, H.J. Blokhuis, P. Costa, R.E. Crilly, T. de Cock Buning, V.C. Delpire, M.J. O'Hare, L.M. Houdebine, C.F. van Kreijl, M. van der Meer, C.A. Reinhardt, E. Wolf and A.M. van Zeller (1998). The Use of Transgenic Animals in the European Union: The Report and Recommendations of ECVAM Workshop 28. Alternatives to Laboratory Animals, 26(1), pp. 21-43. 
Midic, U., P.H. Hung, K.A. Vincent, B. Goheen, P.G. Schupp, D.D. Chen, D.E. Bauer, C.A. VandeVoort and K.E. Latham (2017). Quantitative Assessment of Timing, Efficiency, Specificity, and Genetic Mosaicism of CRISPR/Cas9 Mediated Gene Editing of Hemoglobin Beta Gene in Rhesus Monkey Embryos. Human Molecular Genetics, 26(14), pp. 2678-2689.

Mogil, J.S. (2009). Animal Models of Pain: Progress and Challenges. Nature Reviews Neuroscience, 10(4), pp. 283-294.

Mohiuddin, M.M., A.K. Singh, P.C. Corcoran, M.L. Thomas, T. Clark, B.G. Lewis, R.F. Hoyt, M. Eckhaus, R.N. Pierson, A.J. Belli, E. Wolf, N. Klymiuk, C. Phelps, K.A. Reimann, D. Ayares and K.A. Horvath (2016). Chimeric $2 \mathrm{C}_{10 R} 4$ anti-CD 40 Antibody Therapy Is Critical for Long-term Survival of GTKO.hCD 46.hTBM Pig-to-primate Cardiac Xenograft. Nature Communications, 7, p. 11138.

Morgens, D.W., R.M. Deans, A. Li and M.C. Bassik (2016). Systematic Comparison of CRISPR/Cas9 and RNAi Screens for Essential Genes. Nature Biotechnology, 34(6), pp. $634-636$.

Moura, R.R., L. Melo and V.J. de Figueiredo Freitas (2011). Production of Recombinant Proteins in Milk of Transgenic and Non-transgenic Goats. Brazilian Archives of Biology and Technology, 54, pp. 927-938.

Moyo, B., K. Bloom, T. Scott, A. Ely and P. Arbuthnot (2017). Advances with Using CRISPR/Cas-mediated Gene Editing to Treat Infections with Hepatitis B Virus and Hepatitis C Virus. Virus Research, [Epub ahead of print].

Musunuru, K. (2013). Genome Editing of Human Pluripotent Stem Cells to Generate Human Cellular Disease Models. Disease Models and Mechanisms, 6(4), pp. 896-904.

Nakagawa, Y., T. Sakuma, N. Nishimichi, Y. Yokosaki, N. Yanaka, T. Takeo, N. Nakagata and T. Yamamoto (2016). Ultra-superovulation for the CRISPR-Cas9-Mediated Production of Gene-knockout, Single-amino-acid-substituted, and Floxed Mice. Biology Open, 5(8), pp. 1142-1148.

Niemann, H. and B. Petersen (2016). The Production of Multi-transgenic Pigs: Update and Perspectives for Xenotransplantation. Transgenic Research, 25(3), pp. 361-374.

Nishizaki, S.S. and A.P. Boyle (2017). Mining the Unknown: Assigning Function to Noncoding Single Nucleotide Polymorphisms. Trends in Genetics, 33(1), pp. 34-45.

Niu, Y., B. Shen, Y. Cui, Y. Chen, J. Wang, L. Wang, Y. Kang, X. Zhao, W. Si, W. Li, A.P. Xiang, J. Zhou, X. Guo, Y. Bi, C. Si, B. Hu, G. Dong, H. Wang, Z. Zhou, T. Li, T. Tan, X. $\mathrm{Pu}, \mathrm{F}$. Wang, S. Ji, Q. Zhou, X. Huang, W. Ji and J. Sha (2014). Generation of Genemodified Cynomolgus Monkey via Cas9/RNA-mediated Gene Targeting in One-cell Embryos. Cell, 156(4), pp. 836-843.

Norgren, R.B.J. (2004). Creation of Non-human Primate Neurogenetic Disease Models by Gene Targeting and Nuclear Transfer. Reproductive Biology and Endocrinology, 2, p. 40. 
Nuffield Council on Bioethics (2016). Genome Editing: An Ethical Review. [online] Available at: http://nuffieldbioethics.org/project/genome-editing/ethical-review -published-september-2016 [Accessed: 30 July 2018].

Olsson, I.A. and P. Sandøe (2010). “What's Wrong with My Monkey?” Ethical Perspectives on Germline Transgenesis in Marmosets. Transgenic Research, 19(2), pp. 181-186.

Ormandy, E.H., C.A. Schuppli and D.M. Weary (2009). Worldwide Trends in the Use of Animals in Research: The Contribution of Genetically-modified Animal Models. Alternatives to Laboratory Animals, 37(1), pp. 63-68.

Pattanayak, V., S. Lin, J.P. Guilinger, E. Ma, J.A. Doudna and D.R. Liu (2013). Highthroughput Profiling of Off-target DNA Cleavage Reveals RNA-programmed Cas9 Nuclease Specificity. Nature Biotechnology, 31(9), pp. 839-843.

Peng, R., G. Lin and J. Li (2016). Potential Pitfalls of CRISPR/Cas9-mediated Genome Editing. The FEBS Journal, 283(7), pp. 1218-1231.

Perera, M.T., D.F. Mirza and E. Elias (2009). Liver Transplantation: Issues for the Next 20 years. Journal of Gastroenterology and Hepatology, 24 Suppl 3, pp. S124-31.

Perrin, S. (2014). Preclinical Research: Make Mouse Studies Work. Nature, 507(7493), pp. 423-425.

Petersen, B. and H. Niemann (2015). Molecular Scissors and Their Application in Genetically Modified Farm Animals. Transgenic Research, 24(3), pp. 381-396.

Pratt, J., C. Winchester, N. Dawson and B. Morris (2012). Advancing Schizophrenia Drug Discovery: Optimizing Rodent Models to Bridge the Translational Gap. Nature Reviews. Drug Discovery, 11(7), pp. 560-579.

Proudfoot, C., D.F. Carlson, R. Huddart, C.R. Long, J.H. Pryor, T.J. King, S.G. Lillico, A.J. Mileham, D.G. McLaren, C.B. Whitelaw and S.C. Fahrenkrug (2015). Genome Edited Sheep and Cattle. Transgenic Research, 24(1), pp. 147-153.

Quinn, P.M., L.P. Pellissier and J. Wijnholds (2017). The CRB1 Complex: Following the Trail of Crumbs to a Feasible Gene Therapy Strategy. Frontiers in Neuroscience, 11, p. 175 .

Robinson, V., M. Jennings and G. Working (2004). Refinement and Reduction in the Production of Genetically Modified Mice: Sixth Report of the BVAAWF/FRAME/RSPCA/UFAW Joint Working Group on Refinement. Alternatives to Laboratory Animals, 32(Suppl. 1A), pp. 373-375.

Rollin, B.E. (2015). Telos, Conservation of Welfare, and Ethical Issues in Genetic Engineering of Animals. Current Topics in Behavioral Neurosciences, 19, pp. 99-116.

Rose, M., J. Everitt, H. Hedrich, J. Schofield, M. Dennis, E. Scott, G. Griffin and International Council for Laboratory Animal Sciences (ICLAS) Working Group on Harmonization (2013). ICLAS Working Group on Harmonization: International Guidance Concerning the Production Care and Use of Genetically-altered Animals. Laboratory Animals, 47(3), pp. 146-152. 
Rosen, B., J. Schick and W. Wurst (2015). Beyond Knockouts: The International Knockout Mouse Consortium Delivers Modular and Evolving Tools for Investigating Mammalian Genes. Mammalian Genome, 26(9-10), pp. 456-466.

Ruggeri, B.A., F. Camp and S. Miknyoczki (2014). Animal Models of Disease: Preclinical Animal Models of Cancer and Their Applications and Utility in Drug Discovery. Biochemical Pharmacology, 87(1), pp. 150-161.

Sasaki, E., H. Suemizu, A. Shimada, K. Hanazawa, R. Oiwa, M. Kamioka, I. Tomioka, Y. Sotomaru, R. Hirakawa, T. Eto, S. Shiozawa, T. Maeda, M. Ito, R. Ito, C. Kito, C. Yagihashi, K. Kawai, H. Miyoshi, Y. Tanioka, N. Tamaoki, S. Habu, H. Okano and T. Nomura (2009). Generation of Transgenic Non-human Primates with Germline Transmission. Nature, 459(7246), pp. 523-527.

Schaefer, K.A., W.H. Wu, D.F. Colgan, S.H. Tsang, A.G. Bassuk and V.B. Mahajan (2017). Unexpected Mutations after CRISPR-Casg Editing In Vivo. Nature Methods, 14(6), pp. 547-548.

Schaefer, K.A., B.W. Darbro, D.F. Colgan, S.H. Tsang, A.G. Bassuk and V.B. Mahajan (2018). Corrigendum and Follow-up: Whole Genome Sequencing of Multiple CRISPR-edited Mouse Lines Suggests No Excess Mutations. bioRxiv. Preprint. doi.10.1101/154450.

Servick, K. (2016). Researchers Keep Pig Hearts Alive in Baboons for More Than 2 Years. Science. American Association for the Advancement of Science. [online] Available at: http://www.sciencemag.org/news/2016/o4/researchers-keep-pig -hearts-alive-baboons-more-2-years?utm_campaign=news_daily_2016-04-05\&et _rid=80753971\&et_cid=393886 [Accessed: 30 July 2018].

Shriver, A. (2015). Would the Elimination of the Capacity to Suffer Solve Ethical Dilemmas in Experimental Animal Research?. Current Topics in Behavioral Neurosciences, 19, pp. 117-132.

Skarnes, W.C. (2015). Is Mouse Embryonic Stem Cell Technology Obsolete?. Genome Biology, 16, p. 109.

Sluch, V.M., C.H. Davis, V. Ranganathan, J.M. Kerr, K. Krick, R. Martin, C.A. Berlinicke, N. Marsh-Armstrong, J.S. Diamond, H.Q. Mao and D.J. Zack (2015). Differentiation of Human ESCs to Retinal Ganglion Cells Using a CRISPR Engineered Reporter Cell Line. Scientific Reports, 5, p. 16595.

Snowdon, K. (2016). Chinese Scientists Create "Autistic" Monkeys in "Cruel" Research Study Slammed by Cruelty Free International. Huffington Post. [online] Available at: http://www.huffingtonpost.co.uk/2016/o1/28/chinese-scientists-autistic-monkeys _n_9101858.html [Accessed: 30 July 2018].

Soppe, J.A. and R.J. Lebbink (2017). Antiviral Goes Viral: Harnessing CRISPR/Cas9 to Combat Viruses in Humans. Trends in Microbiology, 25(10), pp. 833-850.

Storer, R.J., W. Supronsinchai and A. Srikiatkhachorn (2015). Animal Models of Chronic Migraine. Current Pain and Headache Reports, 19(1), p. 467. 
Takahashi, K. and S. Yamanaka (2006). Induction of Pluripotent Stem Cells from Mouse Embryonic and Adult Fibroblast Cultures by Defined Factors. Cell, 126(4), pp. $663-676$.

Takahashi, K., K. Tanabe, M. Ohnuki, M. Narita, T. Ichisaka, K. Tomoda and S. Yamanaka (2007). Induction of Pluripotent Stem Cells from Adult Human Fibroblasts by Defined Factors. Cell, 131(5), pp. 861-872.

Taylor, K. and L. Rego (2016). EU Statistics on Animal Experiments for 2014. Alternatives to Animal Experiments, 33(4), pp. 465-468.

Taylor, K., N. Gordon, G. Langley and W. Higgins (2008). Estimates for Worldwide Laboratory Animal Use in 2005. Alternatives to Laboratory Animals, 36(3), pp. 327-342.

Thon, R., J. Lassen, A. Kornerup Hansen, I.M. Jegstrup and M. Ritskes-Hoitinga (2002). Welfare Evaluation of Genetically Modified Mice: An Inventory Study of Reports to the Danish Animal Experiments Inspectorate. Scandinavian Journal of Laboratory Animal Science, 29(1), pp. 45-53.

TNS Opinion \& Social (2010). Science and Technology Report. Special Eurobarometer 340/wave 73.1. [online] Available at: http://ec.europa.eu/public_opinion/archives/ ebs/ebs_340_en.pdf [Accessed: 30 July 2018].

Tsai, S.Q. and J.K. Joung (2016). Defining and Improving the Genome-wide Specificities of CRISPR-Cas9 Nucleases. Nature Reviews, Genetics, 17(5), pp. 300-312.

Tsai, S.Q., Z. Zheng, N.T. Nguyen, M. Liebers, V.V. Topkar, V. Thapar, N. Wyvekens, C. Khayter, A.J. Iafrate, L.P. Le, M.J. Aryee and J.K. Joung (2015). GUIDE-seq Enables Genome-wide Profiling of Off-target Cleavage by CRISPR-Cas Nucleases. Nature Biotechnology, 33(2), pp. 187-197.

U K Home Office (2014). Non-technical Summaries Granted in 2014. [online] Available at: https://www.gov.uk/government/collections/non-technical-summaries-granted -in-2014 [Accessed: 30 July 2018].

u K Home Office (2016). Statistics of Scientific Procedures on Living Animals: Great Britain 2015. [online] Available at: http://www.gov.uk/government/statistics/statistics -of-scientific-procedures-on-living-animals-great-britain-2015 [Accessed: 30 July 2018].

Wang, Z., Q. Pan, P. Gendron, W. Zhu, F. Guo, S. Cen, M.A. Wainberg and C. Liang (2016). CRISPR/Cas9-Derived Mutations Both Inhibit HIV-1 Replication and Accelerate Viral Escape. Cell Reports, 15(3), pp. 481-489.

Webb, D.R. (2014). Animal Models of Human Disease: Inflammation. Biochemical Pharmacology, 87(1), pp. 121-130.

Wells, D.J., L.C. Playle, W.E. Enser, P.A. Flecknell, M.A. Gardiner, J. Holland, B.R. Howard, R. Hubrecht, K.R. Humphreys, I.J. Jackson, N. Lane, M. Maconochie, G. Mason, D.B. Morton, R. Raymond, V. Robinson, J.A. Smith and N. Watt (2006). Assessing the Welfare of Genetically Altered Mice. Laboratory Animals, 40(2), pp. 111-114. 
West, J. and W.W. Gill (2016). Genome Editing in Large Animals. Journal of Equine Veterinary Science, 41, pp. 1-6.

Würbel, H. (2017). More than 3 Rs: The Importance of Scientific Validity for Harmbenefit Analysis of Animal Research. Lab Animal (NY), 46(4), pp. 164-166.

Yang, L., M. Güell, D. Niu, H. George, E. Lesha, D. Grishin, J. Aach, E. Shrock, W. Xu, J. Poci, R. Cortazio, R.A. Wilkinson, J.A. Fishman and G. Church (2015). Genome-wide Inactivation of Porcine Endogenous Retroviruses (PERVS). Science, 350(6264), pp. 1101-1104.

Yang, P., J. Wang, G. Gong, X. Sun, R. Zhang, Z. Du, Y. Liu, R. Li, F. Ding, B. Tang, Y. Dai and N. Li (2008a). Cattle Mammary Bioreactor Generated by a Novel Procedure of Transgenic Cloning for Large-scale Production of Functional Human Lactoferrin. PLoS One, 3(10), p. e3453.

Yang, S.H., P.H. Cheng, H. Banta, K. Piotrowska-Nitsche, J.J. Yang, E.C. Cheng, B. Snyder, K. Larkin, J. Liu, J. Orkin, Z.H. Fang, Y. Smith, J. Bachevalier, S.M. Zola, S.H. Li, X.J. Li and A.W. Chan (2008b). Towards a Transgenic Model of Huntington's Disease in a Non-human Primate. Nature, 453(7197), pp. 921-924.

Yu, S., J. Luo, Z. Song, F. Ding, Y. Dai and N. Li (2011). Highly Efficient Modification of Beta-lactoglobulin (blg) Gene Via Zinc-finger Nucleases in Cattle. Cell Research, 21(11), pp. 1638-1640.

Yue, F., Y. Cheng, A. Breschi, J. Vierstra, W. Wu, T. Ryba, R. Sandstrom, Z. Ma, C. Davis, B.D. Pope, Y. Shen, D.D. Pervouchine, S. Djebali, R.E. Thurman, R. Kaul, E. Rynes, A. Kirilusha, G.K. Marinov, B.A. Williams, D. Trout, H. Amrhein, K. Fisher-Aylor, I. Antoshechkin, G. DeSalvo, L.H. See, M. Fastuca, J. Drenkow, C. Zaleski, A. Dobin, P. Prieto, J. Lagarde, G. Bussotti, A. Tanzer, O. Denas, K. Li, M.A. Bender, M. Zhang, R. Byron, M.T. Groudine, D. McCleary, L. Pham, Z. Ye, S. Kuan, L. Edsall, Y.C. Wu, M.D. Rasmussen, M.S. Bansal, M. Kellis, C.A. Keller, C.S. Morrissey, T. Mishra, D. Jain, N. Dogan, R.S. Harris, P. Cayting, T. Kawli, A.P. Boyle, G. Euskirchen, A. Kundaje, S. Lin, Y. Lin, C. Jansen, V.S. Malladi, M.S. Cline, D.T. Erickson, V.M. Kirkup, K. Learned, C.A. Sloan, K.R. Rosenbloom, B. Lacerda de Sousa, K. Beal, M. Pignatelli, P. Flicek, J. Lian, T. Kahveci, D. Lee, W.J. Kent, M. Ramalho Santos, J. Herrero, C. Notredame, A. Johnson, S. Vong, K. Lee, D. Bates, F. Neri, M. Diegel, T. Canfield, P.J. Sabo, M.S. Wilken, T.A. Reh, E. Giste, A. Shafer, T. Kutyavin, E. Haugen, D. Dunn, A.P. Reynolds, S. Neph, R. Humbert, R.S. Hansen, M. De Bruijn, L. Selleri, A. Rudensky, S. Josefowicz, R. Samstein, E.E. Eichler, S.H. Orkin, D. Levasseur, T. Papayannopoulou, K.H. Chang, A. Skoultchi, S. Gosh, C. Disteche, P. Treuting, Y. Wang, M.J. Weiss, G.A. Blobel, X. Cao, S. Zhong, T. Wang, P.J. Good, R.F. Lowdon, L.B. Adams, X.Q. Zhou, M.J. Pazin, E.A. Feingold, B. Wold, J. Taylor, A. Mortazavi, S.M. Weissman, J.A. Stamatoyannopoulos, M.P. Snyder, R. Guigo, T.R. Gingeras, D.M. Gilbert, R.C. Hardison, M.A. Beer, B. Ren and E.N.C.O.D.E.C. Mouse (2014). A Comparative Encyclopedia of DNA Elements in the Mouse Genome. Nature, 515(7527), pp. 355-364. 
Zou, Q., X. Wang, Y. Liu, Z. Ouyang, H. Long, S. Wei, J. Xin, B. Zhao, S. Lai, J. Shen, Q. Ni, H. Yang, H. Zhong, L. Li, M. Hu, Q. Zhang, Z. Zhou, J. He, Q. Yan, N. Fan, Y. Zhao, Z. Liu, L. Guo, J. Huang, G. Zhang, J. Ying, L. Lai and X. Gao (2015). Generation of Genetarget Dogs Using CRISPR/Cas9 System. Journal of Molecular Cell Biology, 7(6), pp. $580-583$. 